\title{
Bagasse and vinasse, factory wastes from sugarcane industry as potential substrates for bioethanol production
}

\author{
SK Jayasekara ${ }^{1}$, TGY Madusanka ${ }^{2}$, CP Rupasinghe ${ }^{2}$, HAS Weerasinghe ${ }^{3}$, CL Abayasekara ${ }^{4}$, \\ S Seneweera ${ }^{1,5}$ and RR Ratnayake ${ }^{1^{*}}$ \\ ${ }^{1}$ National Institute of Fundamental Studies, Hantana Road, Kandy. \\ ${ }^{2}$ Department of Agriculture Engineering, Faculty of Agriculture, University of Ruhuna, Mapalana, Kamburupitiya. \\ ${ }^{3}$ Division of Crop Nutrition, Sugarcane Research Institute, Uda Walawe. \\ ${ }^{4}$ Department of Botany, Faculty of Science, University of Peradeniya, Peradeniya. \\ ${ }_{5}^{5}$ School of Agriculture and Food, Faculty of Veterinary and Agricultural Sciences, The University of Melbourne, Royal Parade, Parkville, Victoria, \\ 3010, Australia.
}

Submitted: 13 November 2019; Revised: 07 May 2020; Accepted: 18 August 2020

\begin{abstract}
Bagasse and vinasse are byproducts of sugarcanebased sugar and ethanol production. While bagasse is burned for electricity generation, vinasse is underutilised. The current study determined whether the combination of bagasse with vinasse as the carbon source could produce bioethanol. Lignocellulolytic enzyme-producing fungi were evaluated for pretreatment and saccharification of sugarcane bagasse. The vinasse percentage in growth medium which facilitated the maximum growth of yeast and lignocellulolytic fungi was also determined. The most efficient saccharolytic fungi and fermentative yeast were co-cultured in the bagasse + vinasse medium which facilitated their maximum growth. Ethanol was quantified by High-Performance Liquid Chromatography (HPLC) using ethanol standards. Earliella scabrosa (M14) was the most efficient isolate in pretreatment of sugarcane bagasse with $0.764 \mathrm{U} / \mathrm{mL}$ of laccase activity. Aspergillus niger (Fk) was the most efficient isolate in sugarcane bagasse saccharification. Its prolonged incubation period in non-heated/non-washed, washed and heat-treated bagasse types significantly enhanced the bagasse saccharification potential. Results indicated that combining E. scabrosa (M14) with A. niger (Fk) could perform simultaneous pretreatment and saccharification of sugarcane bagasse. A novel finding is that $50 \%$ vinasse + bagasse medium facilitated the maximum growth of lignocellulolytic fungi and fermentative yeast. The highest ethanol yield was given by $A$. niger-Candida tropicalis co-culture (0.005\%) in heat-treated bagasse + Park's mineral salt medium whilst Trichoderma sp. (F2)-C. tropicalis (Y4) co-culture showed the
\end{abstract}

highest ethanol yield $(0.0031 \%)$ in non-heat treated bagasse + vinasse medium. Therefore, vinasse and bagasse are potential substrates for bioethanol production. Further studies on process optimisation will enhance the final ethanol yields.

Keywords: Bioethanol, biological pretreatment and saccharification, fermentative yeast, lignocellulolytic fungi, sugarcane bagasse, vinasse.

\section{INTRODUCTION}

Sugarcane bagasse is the fraction of lignocellulosic biomass which is generated after the extraction of sugarcane juice for sugar production (Robelo et al., 2015). Approximately, 1.6 billion tons of sugarcane from the sugar industry annually produces about 493 million metric tons of bagasse globally (Khattab \& Watanabe, 2019). Although a large quantity of bagasse is burnt in furnaces to generate the necessary vapour and electricity for the sugar factory, a considerable amount is still discarded without being used.

Being a cellulose rich plant residue, sugarcane bagasse could be utilised as a low-cost raw material for ethanol production (Somerville et al., 2010). However, it is a sequential process of converting cellulose into

*Corresponding author (renuka.ra@nifs.ac.lk; (D) https://orcid.org/0000-0002-7667-1447) 
fermentable sugars followed by sugar fermentation to ethanol. The structure of bagasse is complex because the three predominant polymers; lignin, cellulose and hemicellulose form a very rigid interwoven structure. It acts as a barrier which limits the access of saccharifying enzymes to the cellulose component. The removal of the lignin fraction from bagasse, which is mainly defined as pretreatment is therefore essential in order to enhance the exposure of cellulose and hemicellulose to microbial saccharifying enzymes (Pandey et al., 2000; Singh et al., 2008).

Using ligninolytic microorganisms and their enzymes for lignin removal is called biological pretreatment (Khir $\&$ Pan, 2019). The main limitation of this strategy in largescale applications is the prolonged incubation period required for effective delignification. The development of efficient microbial consortia/co-cultures to carry out simultaneous pretreatment and saccharification might be a promising approach of minimizing the incubation period. Thus, there is an urgent need for research and fine-tuning for the development of an economically viable process of pretreatment and saccharification of lignocellulosic biomass (Sindhu et al., 2016).

Vinasse is a distillery effluent which is generated by the sugarcane molasses-based ethanol production process. It is a rich source of sugars and minerals generated by microbial fermentation of sugarcane molasses. Studies of the use of vinasse as an agricultural fertilizer have been documented since the 1940's (Basker et al., 2005). In Brazil, where the sugarcane industry plays a major socioeconomic role, the most common vinasse application is its mixing to the soil of sugarcane fields. As a fertilizer it has high levels of organic matter and nutrients, viz. potassium, nitrogen and phosphorus (Prado et al., 2013; Ortegon et al., 2016). The Crop Nutrition Unit of Sugarcane Research Institute of Sri Lanka has released recommendations for the application of vinasse for sugarcane-growing fields. As per the research conducted by them, application of vinasse to sugarcane plantations has proved to improve the soil organic matter content and the availability of N, P and K in sugarcanegrowing soil, and thereby the performance of plant and ratoon crops of sugarcane. However, these concepts are still underutilised in Sri Lanka.

In the current global scenario, there are reports on the potential use of vinasse for biogas generation and production of biosurfactants (Belhadj et al., 2013; Naspolini et al., 2017). A few other uses of vinasse have also been identified and used in large-scale operations, such as vinasse recycling to fermentation streams (Fadel et al., 2014; Yang et al., 2016), fertirrigation
(Christofoletti et al., 2013; Filoso et al., 2015), energy production, brick manufacturing and animal feed production (Walter et al., 2011).

The current study aimed to investigate the possibility of combining sugarcane bagasse and vinasse with microbial fermentation to produce bioethanol. The study also aimed at identifying efficient lignocellulolytic fungi, with various extracellular enzyme activities in biological pretreatment and saccharification of sugarcane bagasse and to assess the ability of filamentous lignocellulolytic fungi and yeast to grow on vinasse + bagasse medium. It was crucial to understand the possibility of coculturing lignocellulolytic fungi and fermentative yeast in bagasse and vinasse containing fermentation medium, as sugarcane bagasse and vinasse are waste products generated from the sugarcane industry. It was hypothesised that these are potential low-cost substrates or raw materials for bioethanol production.

\section{METHODOLOGY}

\section{Isolation, identification and screening of microorganisms}

\section{Isolation, identification and screening of yeasts}

The isolation of yeasts was done from locally available fruits (e.g. oranges, grapes, sugarcane) (Jayasekara et al., 2017a) as follows. Two grams of each fruit was inoculated into Yeast Extract Peptone Dextrose (YEPD) broth. The resulted culture broths were incubated at $37{ }^{\circ} \mathrm{C}$ for $48 \mathrm{~h}$ in a shaking incubator (Lab Companion, Jeio Tech Co., Ltd, Korea) set at $120 \mathrm{rpm}$. Previously prepared YEPD agar plates supplemented with chloramphenicol $(50 \mathrm{mg} / \mathrm{L})$ were used to obtain discrete yeast colonies from the above broth cultures by streak plate method. Yeasts were purified by repeated sub-culturing on YEPD agar plates. Yeast pure-cultures were maintained at $4{ }^{\circ} \mathrm{C}$ in YEPD agar slants.

The screening of efficient ethanologenic yeast isolates for potential application in bioethanol production has been previously reported (Jayasekara et al., 2017b). In the current study the experiment was conducted in a glucose containing yeast fermentation medium (Slininger et al., 1982 ) and the yeast isolate, Y4 with a $3.6 \%$ ethanol yield was used. The yeast strain, Ysev (Pichia deserticola) was obtained from the Lanka Sugar Company (Pvt.) Limited, Sevanagala Unit for the comparison of final bioethanol yields. According to their Distillery Department, the particular isolate produces $8.5 \%$ ethanol in fermented molasses. 
The yeast isolate (Y4) was identified using molecular biological techniques. Total genomic DNA was extracted from the yeast cells cultured in YEPD broth by incubating the inocula at $37^{\circ} \mathrm{C}$ for $24 \mathrm{~h}$ with shaking at $120 \mathrm{rpm}$. The method previously described as Bust n' Grab Protocol (Harju et al., 2014) was used for DNA extraction. The Internal Transcribed Spacer (ITS) regions of fungal ribosomal RNA were amplified by polymerase chain reaction (PCR) in a thermal cycler (Bio-Rad MyCycler 1.065 PCR Thermal Cycle 563BR) using ITS 1 and ITS 4 primer pair. The cycling profile for the amplification of ITS gene region included an initial denaturation of template DNA at $94{ }^{\circ} \mathrm{C}$ for $5 \mathrm{~min}$, followed by 40 cycles of $94{ }^{\circ} \mathrm{C}$ for $1 \mathrm{~min}$, annealing at $60{ }^{\circ} \mathrm{C}$ for $1 \mathrm{~min}$, elongation at $72{ }^{\circ} \mathrm{C}$ for $1 \mathrm{~min}$ and a final elongation at $72^{\circ} \mathrm{C}$ for $15 \mathrm{~min}$.

PCR products purification and bi-directional DNA sequencing were carried out at Macrogen, South Korea using ABI 3730XL sequencers. The organisms were identified at molecular level using online Basic Local Alignment Search Tool (BLAST) available in National Centre for Biotechnology Information (NCBI) website. The partial sequences obtained in the current study were compared with existing sequences for yeasts in NCBI database using Standard Nucleotide BLAST. The Pairwise Alignment of the nucleotide sequences generated and editing of assembled sequences were done using Geneious Prime 2020.1 software (https://www. geneious.com). The ITS gene sequence for the yeast isolate was deposited in the GenBank.

\section{Isolation, identification and screening of filamentous fungi}

Filamentous fungi were isolated from 52 soil samples collected from nearby forest areas and from decaying logs, leaf litter and plant debris found in a home garden in Kegalle ( $7^{\circ} 15^{\prime} 00.09^{\prime} \mathrm{N} 80^{\circ} 22^{\prime} 42.3^{\prime}$ E). Isolation, initial screening of cellulase enzyme production and morphological identification of the 30 most efficient cellulolytic fungal isolates have been previously reported (Jayasekara et al., 2020). The isolation of fungi was done using conventional microbiological aseptic techniques, with the preparation of a soil dilution series and plating on potato dextrose agar (PDA) (Oxoid ${ }^{\mathrm{TM}}$, UK). The initial total cellulase activity screening was done according to the method described by Mandels and Weber (1969) by using Whatman No.1 filter paper as the substrate. The reducing sugars formed were measured by using dinitro salicylic (DNS) acid reagent (Sumner, 1921; Miller, 1959) against glucose standards. The total cellulase activity was expressed as filter paper units per millilitre (FPU/mL) which is $\mu \mathrm{mol}$ of reducing sugar released by $1 \mathrm{~mL}$ of undiluted enzyme per minute. The morphological identification of filamentous fungi was done using the identification keys described by Barnett and Barry (1998), and Dugan (2006).

\section{Obtaining basidiomycetes}

Earliella scabrosa (M14) and Trametes hirsuta (M40), the basidiomycetes fungi with higher laccase activities (Kathirgamanathan et al., 2017) isolated from the Knuckles forest region of Sri Lanka were obtained from the previously isolated basidiomycetes collection of the same laboratory where the current study was conducted.

\section{Collection of bagasse and vinasse}

Sugarcane bagasse and vinasse samples were collected from the Lanka Sugar Company (Pvt.) Limited, Sevanagala Unit, Sri Lanka. The bagasse was dried at $60{ }^{\circ} \mathrm{C}$ for $24 \mathrm{~h}$ in a laboratory oven (Memmert, Memmert $\mathrm{GmbH}+\mathrm{Co}$., Germany) to remove bulk moisture. The dried bagasse was sifted in a sieving shaker (Ro-Tap, Heiko Seisakusho Ltd., Japan) with $1 \mathrm{~mm}$ mesh size. The resulted fine form bagasse $(<1 \mathrm{~mm})$ was used in the experiment. The collected vinasse was utilised in the experiment devoid of any pre-treatments.

\section{The evaluation of sugarcane bagasse pre-treatment and saccharification potential of fungi}

\section{Selection of fungal isolates}

Ten fungal isolates were evaluated in the current study for their sugarcane bagasse pretreatment and saccharification potential. As previously mentioned, two efficient ligninolytic basidiomycete isolates: E. scabrosa and T. hirsuta (Kathirgamanathan et al., 2017) and eight efficient cellulolytic filamentous fungal isolates which belonged to three main genera, viz. Aspergillus, Trichoderma and Penicillium (Jayasekara et al., 2020) were evaluated. The ten filamentous fungal isolates were F0-Aspergillus green mold, F1-Trichoderma sp., F2-Trichoderma sp., Fasp-Aspergillus black mold, FePenicillium sp., Fh-Aspergillus yellow mold, Fk- $A$. niger and Ft-Trichoderma sp. Filamentous fungi were grown on PDA slants at room temperature $10 \mathrm{~d}$ before the experiment to allow for sporulation. Basidiomycetes were also grown on PDA plates at room temperature.

\section{Culture medium preparation}

The experiment was carried out in $100 \mathrm{~mL}$ Erlenmeyer 
flasks with $30 \mathrm{~mL}$ of Park's mineral salt solution with sugarcane bagasse $(40 \mathrm{~g} / \mathrm{L})$. It was modified from previously described pre-culture medium for fungi (Park et al., 2012). The mineral salt solution consisted of (per liter) $40 \mathrm{~g}$ carbon source (sugarcane bagasse), $24 \mathrm{~g}$ of $\mathrm{KH}_{2} \mathrm{PO}_{4}, 1 \mathrm{~mL}$ of Tween ${ }^{\circledR} 80$ (Sigma-Aldrich Co., USA), $5 \mathrm{~g}$ of $\left(\mathrm{NH}_{4}\right)_{2} \mathrm{SO}_{4}, 4.7 \mathrm{~g}$ of $\mathrm{C}_{4} \mathrm{H}_{4} \mathrm{O}_{6} \mathrm{KNa} .4 \mathrm{H}_{2} \mathrm{O}$, $1.2 \mathrm{~g}$ of $\mathrm{MgSO}_{4} .7 \mathrm{H}_{2} \mathrm{O}, 10 \mathrm{mg}$ of $\mathrm{ZnSO}_{4} .7 \mathrm{H}_{2} \mathrm{O}, 9.28 \mathrm{mg}$ of $\mathrm{MnSO}_{4} \cdot 7 \mathrm{H}_{2} \mathrm{O}, 8.74 \mathrm{mg}$ of $\mathrm{CuSO}_{4} \cdot 7 \mathrm{H}_{2} \mathrm{O}$ and $2 \mathrm{~g}$ of urea ( $\mathrm{pH}$ 4.0). The medium was sterilised at $121{ }^{\circ} \mathrm{C}$ for 20 min. $\mathrm{ZnSO}_{4} \cdot 7 \mathrm{H}_{2} \mathrm{O}, \mathrm{MnSO}_{4} \cdot 7 \mathrm{H}_{2} \mathrm{O}$ and $\mathrm{CuSO}_{4} \cdot 7 \mathrm{H}_{2} \mathrm{O}$ were separately sterilised and added. Urea was sterilized by filtering through a syringe filter membrane $(0.45 \mu \mathrm{m}$, Agilent).

\section{Preparation of bagasse}

Bagasse was prepared in three different forms, viz. non-heated/non-washed bagasse, washed-bagasse and heat-treated bagasse. Washed-bagasse was prepared by washing bagasse under tap water for 10-15 min. After final distilled water wash, the washed-bagasse was dried in the oven at $60{ }^{\circ} \mathrm{C}$ before use. Autoclaved flasks with bagasse and Park's mineral salt solution were maintained at $100{ }^{\circ} \mathrm{C}$ for $1 \mathrm{~h}$ to prepare heat-treated bagasse. The condition was provided using a constant-temperature, benchtop water bath (Gemmyco, Gemmy Industrial Corp., Taiwan).

\section{Fungal inoculum preparation}

After the preparation of three different bagasse containing flasks, the inoculation of fungal isolates into each medium was done in triplicate. Filamentous fungal spores were harvested by adding $1 \mathrm{~mL}$ of sterile $0.1 \%$ $(\mathrm{v} / \mathrm{v})$ Tween $80_{(\mathrm{aq})}$ solution into each slant. The spore concentrations were estimated by using a Neubauer haemocytometer and were adjusted to $10^{7}-10^{8}$ spores/ $\mathrm{mL}$. The inoculum size was $100 \mu \mathrm{L}$ of each fungal spore suspension. The basidiomycetes inoculum was prepared by cutting growing ends of their mycelium on PDA plates into equal size pieces (approximately $5 \times 5 \mathrm{~mm}$ ) using a sterile scalpel. Two such pieces were added into each flask. The cultures were incubated at $28{ }^{\circ} \mathrm{C}$ for 7 days in the shaking incubator set at $100 \mathrm{rpm}$.

Control samples were maintained for each treatment containing non-heated/non-washed bagasse + Park's mineral salt solution, washed-bagasse + Park's mineral salt solution and heat-treated bagasse + Park's mineral salt solution without the fungal inoculum. Each sample contained $1.2 \mathrm{~g}$ of the relevant bagasse type in $30 \mathrm{~mL}$ of mineral salt solution and incubated at the same conditions of the test samples; at $28^{\circ} \mathrm{C}$ for $7 \mathrm{~d}$ in the shaking incubator at $100 \mathrm{rpm}$.

After the first week of incubation, $5 \mathrm{~mL}$ of culture broth was withdrawn from each flask; the volume which is sufficient to conduct the laccase, manganese peroxidase, lignin peroxidase and total cellulase activity assays for each sample. The crude enzymes were extracted by centrifuging the culture broths at $4{ }^{\circ} \mathrm{C}$ and $4500 \mathrm{rpm}$ for $30 \mathrm{~min}$. Crude enzymes were extracted again after $2^{\text {nd }}$ and $4^{\text {th }}$ weeks of incubation and the total cellulase assay was conducted. The purpose of the prolonged incubation step was to study its effect on fungal enzyme production on sugarcane bagasse.

Enzyme assays conducted to evaluate the pretreatment and saccharification potential of fungi

\section{Laccase assay for fungal isolates}

Laccase activity was measured by using ABTS (2, 2'-azino-bis-3-ethylbenzothiazoline-6-sulphonate) as the substrate (Bourbonnais et al., 1995). The assay mixture $(3 \mathrm{~mL})$ contained $0.5 \mathrm{mM}$ ABTS, $100 \mathrm{mM}$ sodium acetate (pH 5.0) and $300 \mu \mathrm{L}$ of crude enzyme. The blank contained $300 \mu \mathrm{L}$ of distilled water with $2700 \mu \mathrm{L}$ of the ABTS solution. The mixture was transferred immediately to a cuvette with a path length of $1 \mathrm{~cm}$ and the absorbance at $420 \mathrm{~nm}$ was read every second for 60 seconds at room temperature. The absorbance was read using the kinetic mode of the UV-Vis spectrophotometer (Cary 60, Agilent Technologies, USA). The enzyme activity of the supernatant was calculated by multiplying the activity of the diluted supernatant by the dilution factor. The amount of oxidized product formed was calculated by using the Beer-Lambert equation, $\mathrm{A}=\varepsilon \mathrm{cl}$, where $\mathrm{A}=$ absorbance, $\varepsilon=$ molar absorptivity, $\mathrm{c}=$ concentration of the analyte and $1=$ path length of the cuvette. The molar absorptivity of $\varepsilon 420=36000 \mathrm{M}^{-1} \mathrm{~cm}^{-1}$ was obtained as described by Reshmi and Sugunan (2013). Final laccase activity was expressed as the amount of product formed, in micromoles per minute by $1 \mathrm{~mL}$ of undiluted culture supernatant.

\section{Manganese peroxidase (MnP) assay for fungal isolates}

The MnP activity was measured by using phenol red as the substrate (Peláez et al., 1995). The reaction mixture ( $3 \mathrm{~mL}$ ) included $0.1 \mathrm{mM} \mathrm{H}_{2} \mathrm{O}_{2}, 0.1 \mathrm{mM} \mathrm{MnSO}, 0.1 \mathrm{mg} /$ $\mathrm{mL}$ phenol red, $100 \mathrm{mM}$ sodium tartrate buffer (pH 5.0) and $1 \mathrm{~mL}$ of crude enzyme. Reaction was stopped by the addition of $120 \mu \mathrm{L}$ of $2 \mathrm{M} \mathrm{NaOH}$ after $30 \mathrm{~min}$. The increase in absorbance at $610 \mathrm{~nm}$ was measured against 
the corresponding enzyme blank (to which $120 \mu \mathrm{L}$ of $2 \mathrm{M}$ $\mathrm{NaOH}$ was added prior to the addition of the reaction mixture) using UV-Vis spectrophotometer. The amount of phenol red oxidized was calculated by using the BeerLambert equation and the molar absorptivity $\varepsilon 610=$ $4460 \mathrm{M}^{-1} \mathrm{~cm}^{-1}$ (Peláez et al., 1995).

\section{Lignin peroxidase assay (LiP) for fungi}

Methylene blue was the substrate used in LiP assay which was performed according to Magalhães et al. (1996). The assay mixture $(3 \mathrm{~mL})$ contained $0.1 \mathrm{~mL}$ of $1.2 \mathrm{mM}$ methylene blue, $0.6 \mathrm{~mL}$ of $0.5 \mathrm{M}$ sodium tartrate $(\mathrm{pH} 4.0)$ and $2.2 \mathrm{~mL}$ of crude enzyme. The reaction was initiated by the addition of $0.1 \mathrm{~mL}$ of $2.7 \mathrm{mM} \mathrm{H}_{2} \mathrm{O}_{2}$. Conversion of the dye to Azure $\mathrm{C}$ was determined by measuring the absorbance at $664 \mathrm{~nm}$ immediately after the addition of $\mathrm{H}_{2} \mathrm{O}_{2}$ and subsequently after $30 \mathrm{~min}$. Enzyme activity was expressed as the decrease in absorbance at $664 \mathrm{~nm}$ per min $(\Delta \mathrm{Abs} / \mathrm{min})$. The blank was prepared by mixing $0.8 \mathrm{~mL}$ of assay reagent with $2.2 \mathrm{~mL}$ of distilled water.

\section{Total cellulase assay for fungi}

The assay was performed using the protocols described by Mandels and Weber (1969) by using Whatman No.1 filter paper as the substrate. The reducing sugars formed were measured by using dinitro salicylic (DNS) acid reagent (Sumner, 1921; Miller, 1959) against glucose standards. The reaction mixture contained Whatman No. 1 filter paper strips ( $50 \mathrm{mg}$ ), $1 \mathrm{~mL}$ of $50 \mathrm{mM}$ citrate buffer ( $\mathrm{pH} 4.8$ for fungi) and $0.5 \mathrm{~mL}$ of crude enzyme. The blank solution contained $0.5 \mathrm{~mL}$ of distilled water with $1 \mathrm{~mL}$ of citrate buffer. The reaction mixture was incubated for $60 \mathrm{~min}$ at $50{ }^{\circ} \mathrm{C}$ in the water bath. Reducing sugars formed were measured by plotting a calibration curve using DNS reagent with glucose standards $(0.5 \mathrm{mg} / \mathrm{mL}$, $1.0 \mathrm{mg} / \mathrm{mL}, 2.0 \mathrm{mg} / \mathrm{mL}$ and $4.0 \mathrm{mg} / \mathrm{mL}$ ).

\section{Bioethanol production in the medium containing bagasse + Park's mineral salt solution}

The method was designed and developed based on the experiment conducted by Park et al. (2012). The experiment was carried out using the sugarcane bagasse ligninolytic fungus and three saccharolytic fungal isolates (E. scabrosa (M14) and the A. niger (Fk) and Trichoderma sp. (F2 and Ft, respectively). These isolates were inoculated into $1000 \mathrm{~mL}$ Erlenmeyer flask with $100 \mathrm{~mL}$ medium. The basidiomycete inoculum consisted of four equal-size pieces of culture growth while $500 \mu \mathrm{L}$ of filamentous fungal spore suspension was inoculated into the medium. The experiment was conducted in triplicates. Two sets of flasks (total 14 flasks including the control sample) were prepared for $\mathrm{Y} 4$ and $\mathrm{Ysev}$ inoculation. The flasks were incubated at $30{ }^{\circ} \mathrm{C}$ with shaking at $120 \mathrm{rpm}$.

Candida tropicalis (Y4) and $P$. deserticola (Ysev) seed cultures were prepared by incubation in YEPD broths separately at $37{ }^{\circ} \mathrm{C}$ for $24-30 \mathrm{~h}$. The yeast seed cultures $(5 \mathrm{~mL})$ were inoculated into the previously two weeks-incubated, ligninolytic and saccharolytic fungi inoculated bagasse + Park's mineral medium containing flasks. The control sample was left without inoculating the yeast. The initial incubation of the co-cultures was done under aerobic conditions at $30{ }^{\circ} \mathrm{C}$ with shaking at $120 \mathrm{rpm}$ for $48 \mathrm{~h}$. During the next $48 \mathrm{~h}$ period, the isolates were incubated in the anaerobic workstation (Bug Box, Ruskinn Technology Ltd., UK) at $30{ }^{\circ} \mathrm{C}$. The atmosphere of the glove box comprised of $90 \% \mathrm{~N}_{2}, 5 \% \mathrm{H}_{2}$ and $5 \% \mathrm{CO}_{2}$. The culture broths were centrifuged using a benchtop centrifuge (Hettich, Andreas Hettich $\mathrm{GmbH} \&$ Co., KG, Germany) at $4{ }^{\circ} \mathrm{C}$ with shaking at $4800 \mathrm{rpm}$ for $15 \mathrm{~min}$. The supernatants filtered through syringe filters (0.45 $\mu \mathrm{m}$, Nylon) were analysed by HPLC (Agilent 1260 Infinity II, Agilent technologies, USA) for the presence of ethanol using Hi-Plex H HPLC column $(300 \times 7.7 \mathrm{~mm}$, Agilent Technologies Manufacturing, Germany) and Refractive Index Detector [RID (Agilent 1260 Infinity II, Agilent technologies, USA)]. The RID and the column temperatures were set at $55^{\circ} \mathrm{C}$. The mobile phase was Milli Q water at a flow rate of $0.7 \mathrm{~mL} / \mathrm{min}$. Ethanol detection and quantification was done using a calibration curve plotted with a series of standards (starting from 2 to $3 \% \mathrm{v} / \mathrm{v}$ ) prepared using ethanol (absolute, for HPLC, $\geq 99.8 \%$, Sigma - Aldrich).

\section{Bioethanol production in the medium containing bagasse + vinasse}

\section{Evaluation of yeast growth in vinasse}

The experiment was designed to find out the vinasse concentration which facilitates the maximum growth of yeast. A dilution series of vinasse was prepared $(0,0.4$, $0.8,2,3,6,12,25,50,75$ and $100 \% \mathrm{v} / \mathrm{v}$ with $30 \mathrm{~mL}$ of final volume) in $100 \mathrm{~mL}$ Erlenmeyer flasks in triplicate and the yeast inoculum was a $24 \mathrm{~h}$ old YEPD broth culture. A $500 \mu \mathrm{L}$ of yeast suspension was inoculated into sterilised vinasse containing flasks. The corresponding blank samples contained each vinasse concentration without the yeast inoculum. The flasks were incubated at $37^{\circ} \mathrm{C}$ with shaking at $120 \mathrm{rpm}$ for $48 \mathrm{~h}$. The absorbance of each broth was read at $600 \mathrm{~nm}$ using the UV-Vis spectrophotometer. 
Evaluation of filamentous fungal growth in bagasse + vinasse medium

The most favourable vinasse concentration for fungal growth was determined as a measure of highest total cellulase activity. The vinasse dilution series $(0,0.2$, $3,6,10,13,16,30,50,60$ and $100 \% \mathrm{v} / \mathrm{v}$ with 30 $\mathrm{mL}$ final volume) in $100 \mathrm{~mL}$ Erlenmeyer flasks were supplemented with oven-dried, $1 \mathrm{~mm}$ size sugarcane bagasse $(40 \mathrm{~g} / \mathrm{L})$. Fungal spore suspension $(100 \mu \mathrm{L}$, $10^{8}$ spores $/ \mathrm{mL}$ ) was inoculated into each flask and incubated at $28{ }^{\circ} \mathrm{C}$ with shaking at $120 \mathrm{rpm}$ for 7 days. The experiment was triplicated for each vinasse concentration. Control samples consisted of vinasse (of respective concentration) + bagasse medium without the fungal inoculum. The vinasse + bagasse medium with the highest total cellulase activity was selected for ethanol production. The experiment was repeated using nonheated/non-washed bagasse + vinasse medium, heatedbagasse + vinasse medium and heated bagasse + Park's mineral salt solution.

\section{Statistical analysis of data}

The collected data were statistically analysed using Minitab version 16. One-way analysis of variance (ANOVA) was done at $95.0 \%$ confidence level. Tukey's pairwise comparison was conducted.

\section{RESULTS AND DISCUSSION}

\section{Molecular biological identification of the yeast isolate}

The sequence in the present study showed $99 \%$ similarity by query coverage and $100 \%$ identity with existing data of Candida tropicalis CTR645 by which the Y4 was identified as Candida tropicalis. The sequence was deposited in the GenBank repository as Candida tropicalis isolate, NIFS-SJ-YEAST under the GenBank Accession number MN796064.

\section{The evaluation of sugarcane bagasse pretreatment} and saccharification potential of fungi

\section{Sugarcane bagasse pretreatment potential of fungal isolates}

Among the ten fungi evaluated, E. scabrosa (M14) resulted in a significantly higher laccase activity $(0.764$ $\mathrm{U} / \mathrm{mL}$ ) on bagasse than the other isolates. Higher laccase activity of a microorganism indicates its higher potential in pretreatment of lignocellulosic biomass. As per the results, E. scabrosa was the most efficient fungal isolate in pretreatment of sugarcane bagasse by performing delignification. In a previous study, the same E. scabrosa isolate showed $0.00912 \mathrm{U} / \mathrm{mL}$ laccase activity in glucose containing medium (Kathirgamanathan et al., (2017). The current study confirmed that the addition of sugarcane bagasse has induced the laccase activity of the isolate. Trichoderma species also have been previously reported as efficient sources of laccase viz; T. atroviride, T. harzianum (Holker et al., 2002) and T. longibrachiatum (Velazquez-Cedeno et al., 2004). However, the current study showed significantly lower laccase activities by Trichoderma isolates (F1, F2 and Ft). Trichoderma sp. $(\mathrm{Ft})$, gave the highest laccase activity $(0.0081 \mathrm{U} / \mathrm{mL})$ which was approximately 94 times lesser in comparison to E. scabrosa's laccase activity.

Manganese peroxidase along with laccase and lignin peroxidases are considered to play a dynamic role in the lignin depolymerization process (Hammel \& Cullen, 2008). The comparison of $\mathrm{MnP}$ activities revealed that the Trichoderma isolates (F1 and F2) demonstrated the highest activities followed by Aspergillus isolates (Fasp and $\mathrm{Fk}$ ). It was also observed that the $\mathrm{MnP}$ activities of evaluated fungi remain below $0.0026 \mathrm{U} / \mathrm{mL}$ which is the highest observed in a Trichoderma sp. (F2). Therefore, $\mathrm{MnP}$ production of the isolates is insignificant when compared with the laccase production of E. scabrosa (M14) for delignification.

The comparison of LiP activities of fungi growing on sugarcane bagasse showed significantly higher activities (0.0034 $\Delta \mathrm{Abs} / \mathrm{mL}$ being the highest) in Trichoderma species (F2, Ft and F1) whilst E. scabrosa (M14) did not produce LiP. Both LiP and MnP activities of fugal isolates were not satisfactory when compared to laccase activity of E. scabrosa. However, basidiomycetes; mainly white-rot fungi are reported to be more efficient in lignin degradation. Phanerochaete chrysosporium is the white rot fungus which is broadly investigated for its efficient ligninolytic properties by LiP and MnP enzyme production (Kersten \& Cullen, 2007).

As per results in the current study, eight filamentous fungal isolates did not produce significant amounts of ligninolytic enzymes. Thus, it appears that their potential application in pretreatment of sugarcane bagasse is very limited. Despite the lower LiP and MnP activities exhibited, E. scabrosa (M14) with significantly higher laccase activities could be efficiently utilised for sugarcane bagasse delignification. 


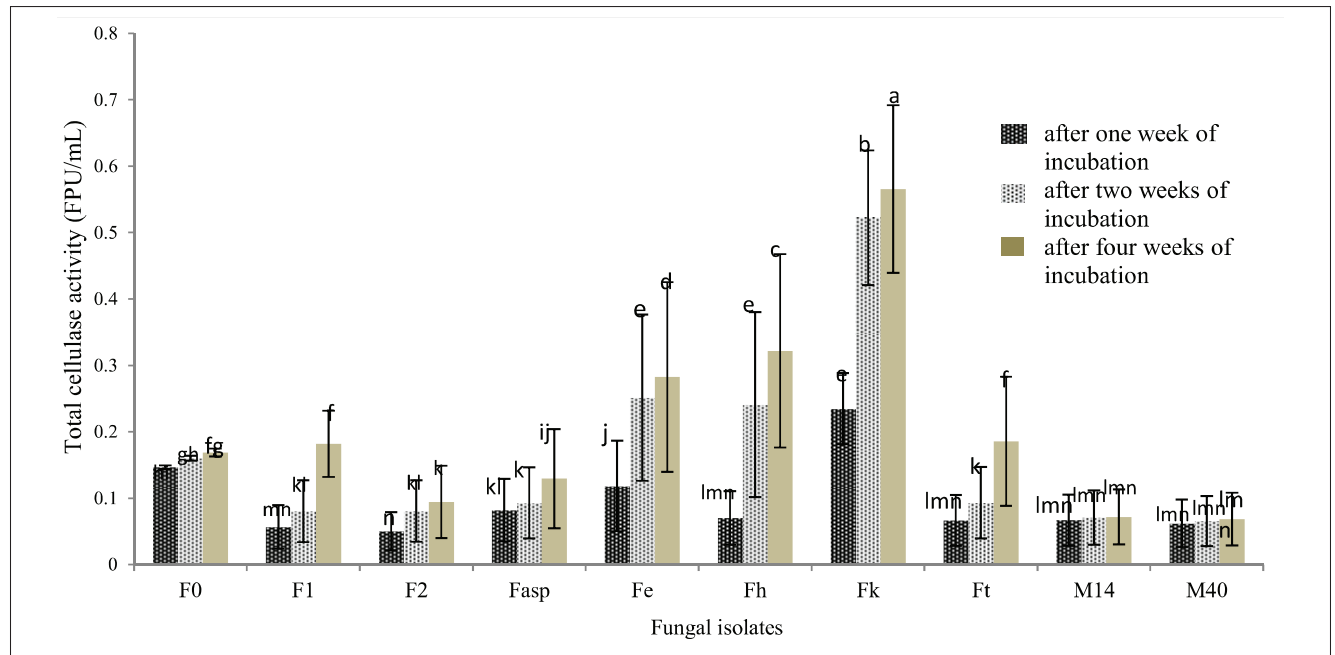

Figure 1: Total cellulase activities of different fungal species on non-washed/non-heated sugarcane bagasse. Error bars indicate the standard errors of the means. Values not sharing the same letter are significantly different $(\mathrm{p}<0.05)$. X axis indicates the fungal isolates: F0 - Aspergillus green mold; F1 - Trichoderma sp.; F 2 Trichoderma sp.; Fasp - Aspergillus black mold; Fe - Penicillium sp.; Fh - Aspergillus yellow mold; Fk - A. niger; Ft - Trichoderma sp.; M14 - E. scabrosa; M40 - T. hirsuta. Y axis indicates the total cellulase activities $(\mathrm{FPU} / \mathrm{mL})$ of respective isolates

\section{Sugarcane bagasse saccharification potential of fungal isolates}

Variation in total cellulase activity among the fungal isolates and the effect of prolonged incubation period on the fluctuations of enzyme activity are illustrated in Figure 1. In comparison to other fungi, A. niger (Fk) showed significantly higher total cellulase activities on sugarcane bagasse. Several recent studies supported the idea of utilising $A$. niger's cellulase production potential in lignocellulosic biomass saccharification. Sridevi et al. (2009) demonstrated high production of cellulase by a local $A$. niger isolate on commercial cellulose and natural lignocelluloses. Another study conducted using the same isolate proved higher rates in saccharifying sawdust (Sridevi et al., 2015). Furthermore, a recent transcriptomic analysis also showed an increased expression of $A$. niger's main cellulase and hemicellulaseencoding genes during the growth on steam-exploded sugarcane bagasse (de Souza et al., 2011). Hence, the application of $A$. niger (Fk) in bagasse could promote efficient saccharification.

Moreover, $A$. niger's total cellulase activity (0.235 FPU/mL) during the first seven day-period of incubation drastically increased up to $0.565 \mathrm{FPU} /$ $\mathrm{mL}$ after four weeks of incubation. It was more than a twofold increment when compared with the initial cellulase activity $(0.235 \mathrm{FPU} / \mathrm{mL})$. Thus, prolonged incubation of fungi on sugarcane bagasse seems to boost cellulase activity and hence the saccharification of bagasse to release fermentable sugars. However, long biodegradation periods cannot be considered as advantageous in an industrial pretreatment and saccharification application (Zheng et al., 2009).

In addition, fungi produce toxic metabolites (mycotoxins) during their growth. Aspergillus niger, which is one of the most widely utilised microorganisms in industrial fermentations (Blumenthal, 2004), produces a series of secondary metabolites including toxins like ochratoxin A and fumonisin $\mathrm{B}_{2}$ (Schuster et al., 2002; Soares et al., 2012). As they are considered carcinogenic to humans and animals, it is important to conduct toxin analysis for the selected fungal isolates. It is also believed that mycotoxins stress the yeast during fermentation, resulting in lower ethanol yields (Kelsall \& Lyons, 2003). Moreover, in the downstream process, handling wastes containing toxins could cause health risks. Therefore, based on the toxin analysis, safety precautions and proper waste disposal methods must be established as necessary.

Effect of washed-bagasse on fungal cellulase production

As per total cellulase activities, Aspergillus green 
mold (F0), Trichoderma sp. (F1), Penicillium sp. (Fe), Aspergillus yellow mold (Fh) and A. niger (Fk) which exhibited comparatively higher results (Figure 1) were grown on washed bagasse. The initial cellulase activity (0.458 FPU $/ \mathrm{mL})$ of $A$. niger (Fk) in washed-bagasse significantly increased up to $0.57 \mathrm{FPU} / \mathrm{mL}$ after two weeks (Figure 2). In addition, the initial enzyme activity of $A$. niger on washed-bagasse $(0.458 \mathrm{FPU} / \mathrm{mL})$ was significantly higher than the cellulase production $(0.235$ FPU/mL) on non-washed/non-heated bagasse $(\mathrm{p}<0.05)$.

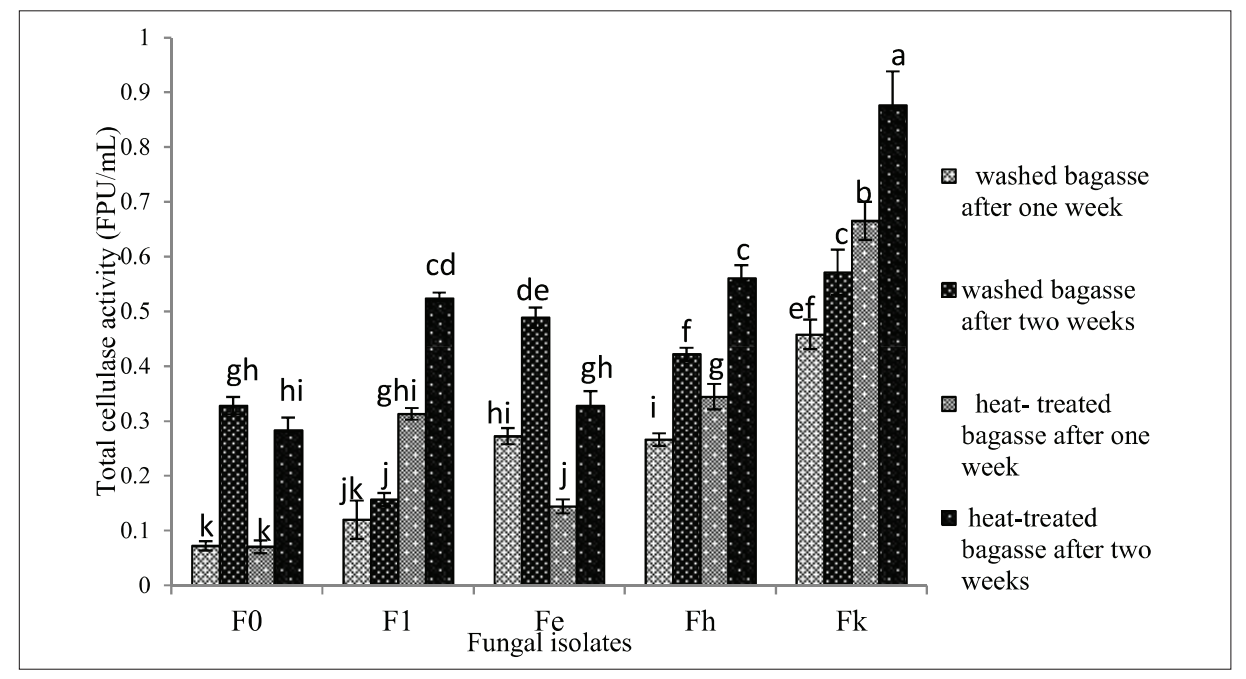

Figure 2: Saccharification of heat-treated bagasse and washed bagasse using different fugal isolates. Error bars indicate the standard errors of the means. Values not sharing the same letter are significantly different $(\mathrm{p}<0.05)$. X axis indicates the fungal isolates: F0 - Aspergillus green mold; F1 Trichoderma sp.; Fe - Penicillium sp.; Fh - Aspergillus yellow mold; Fk - A. niger sp. Y axis indicates the total cellulase activities (FPU/mL) of respective isolates after one week and two weeks of incubation in respective bagasse medium

Thus, a prior-washing step could impose a significant positive impact on enhanced cellulolysis of fungal isolates.

A recent study (Sasaki et al., 2012) reported similar observations that washing steam-exploded bagasse with water before enzymatic hydrolysis improved the final glucose yields. The study further emphasised that the increased glucose yield is due to the removal of microbial fermentation inhibitors on sugarcane bagasse. In a different study, A. niger and T. reesei were evaluated for the production of hydrolytic enzymes on wheat straw and sugarcane bagasse before and after washing with water and have also observed an increase in cellulolytic activities after washing (van den Brink et al., 2014). Therefore, using washed-bagasse might be an effective method of accelerating the fungal saccharification of bagasse.

The removal of easily fermentable sugar forms on bagasse might have induced the fungal cellulase production in washed-bagasse supplemented growth medium. The rapid metabolism of fermentable sugars over more complex cellulose for growth might have resulted in the significant cellulase activity decrease in non-washed bagasse.

An HPLC analysis of initial water-soluble sugars in sugarcane bagasse sample confirmed the presence of glucose and xylose residues at $7.9 \mathrm{~min}$ and $8.4 \mathrm{~min}$ retention times respectively. When the bagasse was washed off, these two peaks disappeared from the HPLC chromatogram. Glucose and xylose are preferred carbon sources for fungal growth and studies have shown that the genes encoding hydrolytic enzymes involved in plant cell wall deconstruction in filamentous fungi can be repressed during their growth in the presence of easily metabolizable carbon sources. This important mechanism is called carbon catabolite repression (de Vries \& Visser, 2001; Kubicek et al., 2009). Hence there is a possibility that, when the fungi were grown in non-washed bagasse, the enzyme production might have initially been repressed due to the presence of fermentable sugars. 


\section{Effect of heat-treated bagasse on fungal cellulase production}

The total cellulase activity of $A$. niger (Fk) reached up to a highest level $(0.877 \mathrm{FPU} / \mathrm{mL})$ in heat-treated bagasse after two weeks of incubation (Figure 2). The comparison of enzyme activities on heat-treated and non-heat treated bagasse showed significantly higher increments in F1, Fh and Fk isolates on heat-treated bagasse while $A$. niger showed the highest increase from $0.235 \mathrm{FPU} / \mathrm{mL}$ to $0.665 \mathrm{FPU} / \mathrm{mL}$ after one week of incubation $(\mathrm{p}<0.05)$. Accordingly, providing a heat treatment to bagasse before the inoculation of saccharifying fungi could be a promising way of enhancing the bagasse saccharification. Several previous studies supported this idea of applying heat to enhance the microbial biomass saccharification while steam explosion and liquid hot water application are the most widely studied lignocellulosic biomass heat treatment methods (Olivia et al., 2003; Ramos et al., 2015; Gurgel et al., 2016).

Heat could change the ultra-structure of cellulose by degrading lignin and hemicelluloses, increasing the enzymatic susceptibility of lignocellulosic materials (Maurya et al., 2013). Using physical methods (heating, washing) in combination with microbial methods might enhance the pretreatment process. However, it is essential to find low cost sources of heat for pretreatment. For instance, the initial temperature of discarded vinasse from the distillery is above $90{ }^{\circ} \mathrm{C}$, and if the heat energy incorporated in hot vinasse could be trapped with a suitable energy trapping technique or a device there is a huge potential of using it to pretreat bagasse. It will be a novel, low cost as well as an ecofriendly approach of providing heat for bagasse pretreatment.

\section{Bioethanol production}

\section{Potential use of vinasse in culture media preparation for fungi}

The maximum growth of the yeast isolate, $C$. tropicalis (Y4) was observed in the $50 \%$ vinasse solution (Figure 3). Most importantly, the addition of any commercially available culture media components was not done to fortify the vinasse solution. The optimum growth was observed by adjusting the concentration of vinasse in the medium using sterile distilled water. Thus, vinasse could be used for formulation of culture media for yeast.

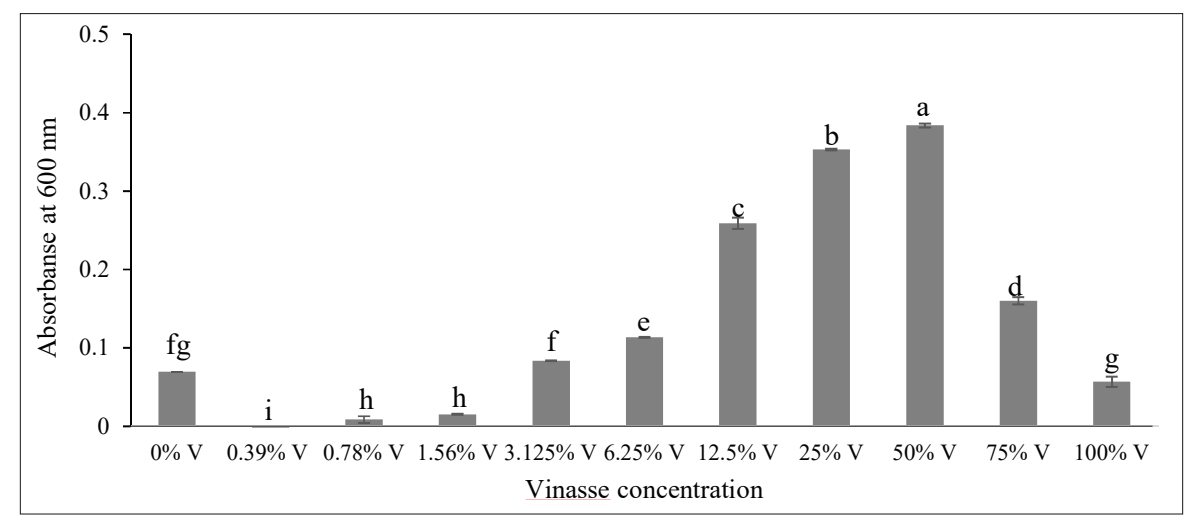

Figure 3: The yeast growth in different vinasse concentrations after $48 \mathrm{~h}$ of incubation. Error bars indicate the standard errors of the means. Values not sharing the same letter are significantly different $(\mathrm{p}<0.05)$. 'V' denotes the abbreviation of 'Vinasse'

The $50 \%$ vinasse + bagasse medium facilitated the significantly highest total cellulase activity of $A$. niger (Fk). The recorded total cellulase activity was $1.45 \mathrm{FPU} /$ $\mathrm{mL}(\mathrm{p}<0.05)$. It was higher than the previously observed total cellulase activity $(0.23 \mathrm{FPU} / \mathrm{mL})$ by the same isolate in non-washed/non-heated bagasse + Park's mineral salt solution (Figure 1). The mineral salt solution was completely replaced by vinasse. Therefore, this medium could be developed as a low cost method to co-culture yeast and cellulolytic fungi for bioethanol production from sugarcane bagasse.

\section{Bioethanol production on sugarcane bagasse}

The ethanol yield comparison was done based on the non-heat treated/non-washed bagasse + Park's mineral 


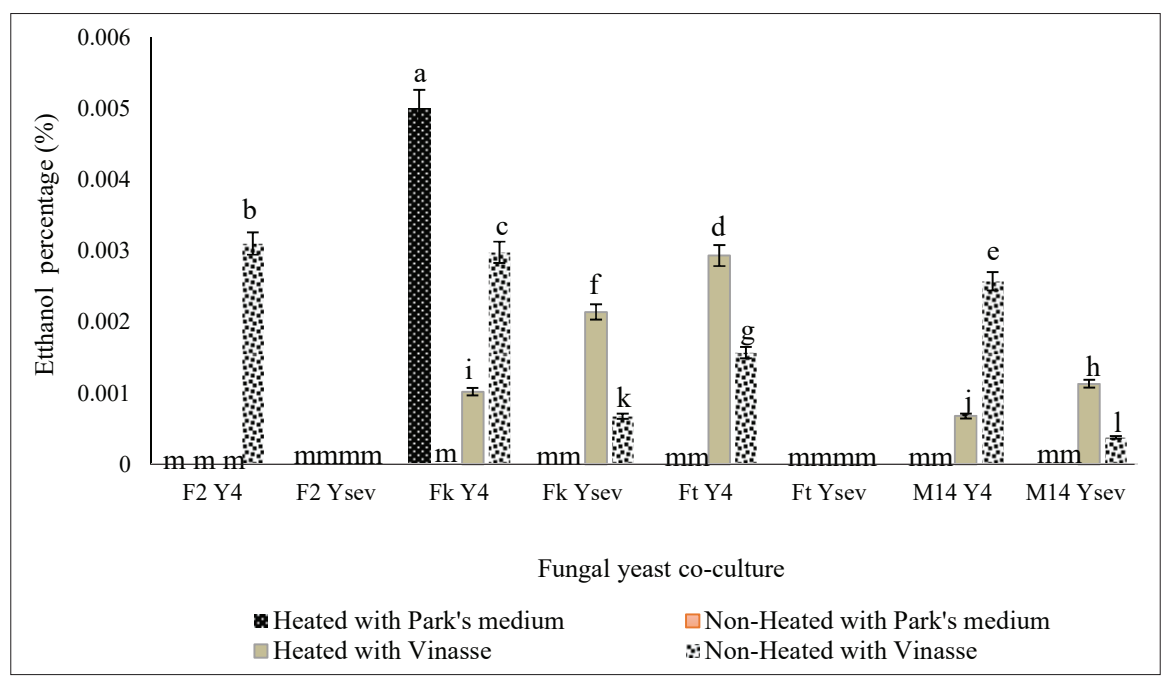

Figure 4: The ethanol production of yeast-fungi co-cultures on sugarcane bagasse containing fermentation media. Error bars indicate the standard errors of the means. Values not sharing the same letter are significantly different $(\mathrm{p}<0.05)$. $\mathrm{X}$ axis indicates fungal-yeast cocultures: F2Y4 - Trichoderma sp./ C. tropicalis co-culture; F2Ysev - Trichoderma sp./ P. deserticola co-culture; FkY4 - Aspergillus sp./ P. deserticola co-culture; FtY4 - Trichoderma sp./ C. tropicalis co-culture; FtYsev - Trichoderma sp/ P. deserticola co-culture; M14Y4E. scabrosa/ C. tropicalis co-culture; M14Ysev- E. scabrosa/ P. deserticola co-culture. Y axis: ethanol percentage

salt solution as the control medium. The particular medium was not preferred by yeast-fungi co-cultures for ethanol production. As per results, A. niger (Fk)-C. tropicalis (Y4) co-culture was the most efficient in ethanol production as it gave ethanol in all the treatments except in non-heat treated/non-washed bagasse + Park's mineral medium (Figure 4).

Moreover, C. tropicalis (Y4) was observed to be more efficient in ethanologenesis than the commercial yeast isolate, $P$. deserticola (Ysev). The $P$. deserticolaTrichoderma sp. co-cultures were not efficient in ethanologenesis when compared with $C$. tropicalis cocultures. Accordingly, P. deserticola, being an efficient ethanologenic monoculture in sugarcane molasses-based commercial ethanol production, was not well-adapted to the conditions provided in the current study. On the contrary, there is a potential to further develop the C. tropicalis co-cultures with cellulolytic Aspergillus sp. and Trichoderma sp. to enhance the ethanol yields.

Most importantly, $75 \%$ of the total co-cultures evaluated ( 6 out of 8 ) were able to produce ethanol in non-heated/non-washed bagasse + vinasse containing medium which is the waste product generated from sugarcane industry. If it is possible to use these materials in ethanol production without providing specific pretreatments, except the microbial hydrolysis it could be a promising way of producing ethanol in a profitable manner. In addition, heat-treated bagasse samples gave significantly higher ethanol yields in comparison with the non-heat treated bagasse samples. Therefore, ethanol yields of the co-cultures could be enhanced by heat treatment of bagasse medium.

Currently, research on utilisation of different lignocellulosic biomass for bioethanol production has shown very promising results worldwide. Several lab and pilot scale studies for cellulosic ethanol production have also been reported as being successful (Saini et al., 2015). In this regard, bioethanol production using lignocellulosic biomass, viz. rice hulls (Dagnino, et al., 2013), bagasse (Martín et al., 2002), corn stover (Kazi et al., 2010) wood bark, forest residues and switch grass (Hu et al., 2008) and agriculture residue (Demirbas, 2009) has been studied. The yields given by each biomass varied on various parameters including pretreatment methods used, provided temperature, $\mathrm{pH}$ and fermentation methods.

In a very recent study, $22.77 \mathrm{~g} / \mathrm{L}$ of bioethanol was produced using a mixture of rice hull and orange peel 
wastes (Taghizadeh-Alisarae et al., 2019). However, their substrate hydrolysis method which included sulphuric acid (3\%) was not a cost effective or an environmental friendly approach. In another study the rice husk feedstocks gave an ethanol yield of $3.011 \pm$ $0.034 \%$ (Madu \& Agboola, 2018). The study included a $\mathrm{FeCl}_{3}$ chemical pretreatment method. A different study conducted on sugarcane bagasse yielded $12 \%$ of ethanol in a fluidized bed bioreactor assisted by a magnetic field (Dussán et al., 2019). The highest ethanol yield given in the current experiment was $0.0051 \%$ which is comparatively lower than the previously reported yields. In spite of the fact that the yield is low, the current study attempted to emphasise the importance of using highly abundant and renewable raw materials such as vinasse and bagasse in an environment-friendly and sustainable manner. In a laboratory scale approach, the study has already proved that these raw materials could be utilised to produce ethanol using ethanologenic yeast and lignocellulolytic fungal co-cultures. Sugarcane bagasse and vinasse are abundant not only in Sri Lanka but also in many countries in the world. Optimising the current method will assist in advocating these waste materials as a key feedstock for cost-effective bioethanol production. Therefore, further studies must be conducted to optimise the process conditions. It could be accomplished by media formulations, adjusting the optimum growth parameters for microorganisms and efficient recovery and purification of final product. In addition, recent advancements in genetic engineering techniques will enable to improve microbial strains (Hatti-Kaul et al., 2007; Chandel \& Singh, 2011). Genetic modifications will lead to enhanced ligninolytic, saccharolytic and ethanologenic efficiencies of the wild type microbial isolates described in the study. Moreover, applying physical pretreatment methods such as washing and heating enhanced the sugarcane bagasse pretreatment and saccharification potential of microbial isolates. However, incorporation of these strategies into sugarcane bagasse + vinasse based bioethanol production must be done with caution. The sources of water and heat used neither should adversely affect the environment nor increase the production cost.

\section{CONCLUSION}

Earliella scabrosa (M14) was the most efficient isolate recorded in the current study for pretreatment of sugarcane bagasse with $0.764 \mathrm{U} / \mathrm{mL}$ laccase activity. Although Trichoderma isolates (F1, F2 and Ft) expressed the highest $\mathrm{MnP}$ and LiP enzyme activities, overall ligninolytic enzyme production of filamentous fungi was negligible when compared with E. scabrosa's laccase production. Aspergillus niger (Fk) was recorded as the most efficient in sugarcane bagasse saccharification, and its sugarcane bagasse saccharification potential was drastically increased with prolonged incubation in washed and heat-treated sugarcane bagasse medium. A $50 \%$ vinasse solution facilitated the maximum yeast growth, and it could be used in yeast culture media preparation. The highest total cellulase activity (1.45 $\mathrm{FPU} / \mathrm{mL}$ ) of $A$. niger (Fk) was given in $50 \%$ vinasse + bagasse medium. The combination of E. scabrosa, the efficient lignin degrading basidiomycete with the A. niger (Fk), the most efficient saccharolytic fungus could be used for simultaneous pretreatment and saccharification of sugarcane bagasse. Aspergillus niger (Fk) - C. tropicalis (Y4) co-culture resulted in the highest ethanol yield $(0.005 \%)$ in heated bagasse + Park's mineral medium. Trichoderma sp. (F2) - C. tropicalis (Y4) co-culture resulted in the highest ethanol yield $(0.0031 \%)$ on non-heated bagasse + vinasse medium. A novelty of the current study is the potential of producing bioethanol using co-cultures of lignocellulolytic fungi and fermentative yeast in bagasse + vinasse medium. In addition, another important finding was that $50 \%$ vinasse, without any pretreatment could be utilised in formulating culture media for growing lignocellulolytic fungi and fermentative yeast. While concluding that sugarcane bagasse and vinasse are potential substrates for bioethanol production, further studies on process optimisation of ethanol production using vinasse + bagasse medium should lead to higher yields of ethanol. The efficient yeast-fungi co-cultures introduced in the current study could be further investigated for potential application in bioethanol production using various lignocellulosic biomasses. These findings could cause economically important impacts in fuel bioethanol production using low cost substrates. Moreover, the researchers in the area of bioethanol production will find this study interesting and novel ideas may evolve for further studies.

\section{Conflicts of Interest}

All authors declare that there are no conflicts of interest.

\section{Acknowledgements}

The authors acknowledge the support given by Dr Mohanan Kathirgamanathan (Former NIFS Research Assistant), Scientist, Genetech Molecular Diagnostic \& School for Gene Technology, Sri Lanka and Mrs Kumuduni Karunarathe, Chief Technical Officer, National Institute of Fundamental Studies for culture maintenance and laboratory analyses. National Science 
Foundation of Sri Lanka is also gratefully acknowledged for awarding the equipment grant (No: RG/2015/EQ/04) to purchase an HPLC system.

\section{REFERENCES}

Barnett H.L. \& Hunter B.B. (1998). Illustrated Genera of Imperfect Fungi, $4^{\text {th }}$ edition. APS Press, Minnesota, USA.

Baskar M., Gopal H., Sheik M. \& Bose M.S.C. (2005). Effect of integrated use of distillery effluent and fertilisers on soil properties and yield of sugarcane in sandy loam soil. The Madras Agricultural Journal 92(4-6): 349-354.

Belhadj S., Karouach F., El Bari H. \& Joute Y. (2013). The biogas production from mesophilic anaerobic digestion of vinasse. IOSR Journal of Environmental Science, Toxicology and Food Technology 5(6): 72-77. DOI: https://doi.org/10.9790/2402-0567277

Blumenthal C.Z. (2004). Production of toxic metabolites in Aspergillus niger, Aspergillus oryzae, and Trichoderma reesei: justification of mycotoxin testing in food grade enzyme preparations derived from the three fungi. Regulatory Toxicology and Pharmacology 39(2): 214-228. DOI: https://doi.org/10.1016/j.yrtph.2003.09.002

Bourbonnais R., Paice M.G., Reid I.D., Lanthier P. \& Yaguchi M. (1995). Lignin oxidation by laccase isozymes from Trametes versicolor and role of the mediator 2 , 2'-azinobis (3-ethylbenzthiazoline-6-sulfonate) in kraft lignin depolymerization. Applied and Environmental Microbiology 61: 1876-1880.

DOI: https://doi.org/10.1128/AEM.61.5.1876-1880.1995

Chandel A.K. \& Singh O.V. (2011). Weedy lignocellulosic feedstock and microbial metabolic engineering: advancing the generation of 'biofuel'. Applied Microbiology and Biotechnology 89: 1289-1303.

DOI: https://doi.org/10.1007/s00253-010-3057-6

Christofoletti C.A., Escher J.P., Correia J.E., Marinho J.F.U. \& Fontanetti C.S. (2013). Sugarcane vinasse: environmental implications of its use. Waste Management 33: 2752-2761. DOI: https://doi.org/10.1016/j.wasman.2013.09.005

Dagnino E., Chamorro E., Romano S., Felissia F. \& Area M. (2013). Optimisation of the acid pretreatment of rice hulls to obtain fermentable sugars for bioethanol production. Industrial Crops and Products 42: 363-368.

DOI: https://doi.org/10.1016/j.indcrop.2012.06.019

de Souza W.R., de Gouvea P.F. \& Savoldi M. (2011). Transcriptome analysis of Aspergillus niger grown on sugarcane bagasse. Biotechnology for Biofuels 4: 40 DOI: https://doi.org/10.1186/1754-6834-4-40.

de Vries R.P. \& Visser J.(2001). Review Aspergillus enzymes involved in degradation of plant cell wall polysaccharides. Microbiology and Molecular Biology Reviews 65(4): 497522.

DOI: https://doi.org/10.1128/MMBR.65.4.497-522.2001

Demirbas A. (2009). Biofuels securing the planet's future energy needs. Energy Conversion and Management 50(9): 2239-2249.

DOI: https://doi.org/10.1016/j.enconman.2009.05.010

Dugan F.M. (2006). The Identification of Fungi. APS Press,
Minessota, USA.

Dussán K.J., Justo O.R. \& Perez V.H. (2019). Bioethanol production from sugarcane bagasse hemicellulose hydrolysate by immobilized $S$. shehatae in a fluidized bed fermenter under magnetic field. Bioenergy Research 12: 338-346. DOI: https://doi.org/10.1007/s12155-019-09971-y

Fadel M., Zohri A.-N. A., Makawy M., Hsona M., \& Abdel-Aziz A. (2014). Recycling of vinasse in ethanol fermentation and application in Egyptian distillery factories. African Journal of Biotechnology 13: 4390-4398.

DOI: https://doi.org/10.5897/AJB2014.14083

Filoso S., do Carmo J.B., Mardegan S.F., Lins S.R.M. Gomes T.F. \& Martinelli L.A. (2015). Reassessing the environmental impacts of sugarcane ethanol production in Brazil to help meet sustainability goals. Renewable and Sustainable Energy Reviews 52: 1847-1856.

DOI: https://doi.org/10.1016/j.rser.2015.08.012

Gurgel L.V.A., Pimenta M.T.B. \& Curvelo A.A.S. (2016). Ethanol-water organosolv delignification of liquid hot water (LHW) pretreated sugarcane bagasse enhanced by high-pressure carbon dioxide $\left(\mathrm{HP}-\mathrm{CO}_{2}\right)$. Industrial Crops and Products 94: 942-950.

DOI: https://doi.org/10.1016/j.indcrop.2016.10.003

Hammel K.E. \& Cullen D. (2008). Role of fungal peroxidases in biological ligninolysis. Current Opinion in Plant Biology 11: $349-355$.

DOI: https://doi.org/10.1016/j.pbi.2008.02.003

Harju S., Fedosyuk H. \& Peterson K.R. (2014). Rapid isolation of yeast genomic DNA: Bust n' Grab Protocol. BMC Biotechnology 4: 8 .

DOI: https://doi.org/10.1186/1472-6750-4-8

Hatti-Kaul R., Tornvall U., Gustafsson L. \& Borjesson P. (2007). Industrial biotechnology for the production of biobased chemicals a cradleto-grave perspective. Trends in Biotechnology 25: 119-124.

DOI: https://doi.org/10.1016/j.tibtech.2007.01.001

Holker U., Dohse J. \& Hofer M. (2002). Extracellular laccases in ascomycetes Trichoderma atroviride and Trichoderma harzianum. Folia Microbiologica 47(4): 423-427. DOI: https://doi.org/10.1007/BF02818702

Hu G., Heitmann J. A. \& Rojas O. J. (2008). Feedstock pretreatment strategies for producing ethanol from wood, bark, and forest residues. BioResources 3(1): 270- 294.

Jayasekara S.K., Kathirgamanathan M. \& Ratnayake R.R. (2020). Isolation, identification and studying the potential application of tropical fungi in lignocellulolysis. In: Research Advances in the Fungal World: Culture, Isolation, Identification, Classification, Characterization, Properties and Kinetics (eds. P.K. Chaurasia \& S.L. Bharati), pp. 3559. Nova Science Publishers, New York, USA.

Jayasekara S.K., Abayasekara C.L. \& Ratnayake R.R. (2017b). Screening local fungal isolates for their cellulases production: the applicability in producing bioethanol from cellulose. In: Proceedings of the International Research Symposium on Pure and Applied Sciences. Faculty of Science, University of Kelaniya, Sri Lanka, 20 October, pp. 47. 
Jayasekara S.K., Abayasekara C.L., Ratnayake R.R. (2017a). Isolation and characterization of yeast strains for bioethanol production. In: Proceedings of the $4^{\text {th }}$ International Conference on Multidisciplinary Approaches. Hikkaduwa, Sri Lanaka. 20-22 September. Faculty of Graduate Studies, University of Sri Jayewardenepura, Nugegoda, Sri Lanka, pp. 149.

Kathirgamanathan M., Abayasekara C.L., Kulasooriya S.A., Wanigasekera A. \& Ratnayake R.R. (2017). Evaluation of 18 isolates of basidiomycetes for Lignocellulose degrading enzymes. Ceylon Journal of Science 46(4): 77-84. DOI: http://doi.org/10.4038/cjs.v46i4.7470

Kazi F.K., Fortman J.A., Anex R.P., Hsu D.D., Aden A., Dutta A. \& Kothandaraman G. (2010). Techno-economic comparison of process technologies for biochemical ethanol production from corn stover. Fuel 89: 20-28. DOI: https://doi.org/10.1016/j.fuel.2010.01.001

Kelsall D.R. \& Lyons T.P. (2003). Practical management of yeast: Conversion of sugars to ethanol. In: The Alcohol Textbook: A Reference for the Beverage, Fuel and Industrial Alcohol Industries, $4^{\text {th }}$ edition (eds. K. A. Jacques, T.P. Lyons \& D.R. Kelsall), pp.125-129. Nottingham University Press, Nottingham, UK.

Kersten P. \& Cullen D. (2007). Extracellular oxidative systems of the lignin degrading basidiomycete Phanerochaete chrysosporium. Fungal Genetics and Biology 44: 77-87. DOI: https://doi.org/10.1016/j.fgb.2006.07.007

Khattab S.M.R. \& Watanabe T. (2019). bioethanol from sugarcane bagasse: status and perspectives. In: Bioethanol Production from Food Crops (eds. R.C. Ray \& S. Ramachandran), pp. 187-212. Academic Press, Cambridge, USA.

DOI: https://doi.org/10.1016/B978-0-12-813766-6.00010-2

Khir R. \& Pan Z. (2019). Rice. In: Integrated Processing Technologies for Food and Agricultural By-Products (eds. Z. Pan, R. Zhang \& S. Zicari), pp. 21-58. Academic Press, Cambridge, USA.

DOI: https://doi.org/10.1016/B978-0-12-814138-0.00002-2.

Kubicek C.P., Mikus M., Schuster A., Schmoll M. \& Seiboth B. (2009). Metabolic engineering strategies for the improvement of cellulase production by Hypocrea jecorina. Biotechnology for Biofuels 2: 19(2019).

DOI: https://doi.org/10.1186/1754-6834-2-19

Madu J. O. \& Agboola B. O. (2018). Bioethanol production from rice husk using different pretreatments and fermentation conditions. 3 Biotech 8: 15(2018). DOI: https://doi.org/10.1007/s13205-017-1033-X

Magalhães D.B., Carvalho M.E.A., Bon E., Neto J.S.A. \& Kling S.H. (1996). Colorimetric assay for lignin peroxidase activity determination using methylene blue as substrate. Biotechnology Techniques 10: 273 - 276. DOI: https://doi.org/10.1007/BF00184028

Mandels M. \& Weber J. (1969). Cellulases and its Application. Advances in Chemistry Series, pp. 391-414. American Chemical Society, Washington DC, USA. DOI: https://doi.org/10.1021/ba-1969-0095.ch023

Martín C., Galbe M., Wahlbom C.F., Hahn-Hägerdal B. \& Jönsson L.J. (2002). Ethanol production from enzymatic hydrolysates of sugarcane bagasse using recombinant xylose-utilising Saccharomyces cerevisiae. Enzyme and Microbial Technology 31(3): 274-282.

DOI: https://doi.org/10.1016/S0141-0229(02)00112-6

Maurya D.P., Vats S., Rai S. \& Negi S. (2013). Optimisation of enzymatic saccharification of microwave pretreated sugarcane tops through response surface methodology for biofuel. Indian Journal of Experimental Biology 51: 992-996.

Miller G.L. (1959). Use of dinitrosalicylic acid reagent for determination of reducing sugar. Analytical Chemistry 31(3): 426-428.

DOI: https://doi.org/10.1021/ac60147a030

Naspolini B.F., Machado A.C. de O., Junior W.B.C., Freire D.M.G. \& Cammarota M.C. (2017). Bioconversion of Sugarcane Vinasse into High-Added Value Products and Energy. BioMed Research International 2017: Article ID 8986165 .

DOI: https://doi.org/10.1155/2017/8986165

Olivia J.M., Sáez F., Ballesteros I., González A., Negro M.J. \& Manzanares P. (2003). Effect of lignocellulosic degradation compounds from steam explosion pretreatment on ethanol fermentation by thermotolerant yeast Kluyveromyces marxianus. Applied Microbiology and Biotechnology 105: 141-154.

DOI: https://doi.org/10.1385/ABAB:105:1-3:141

Ortegón G. P., Arboleda F. M., Candela L., Tamoh K. \& ValdesAbellan J. (2016). Vinasse application to sugar cane fields. Effect on the unsaturated zone and groundwater at Valle del Cauca (Colombia). Science of the Total Environment 539: 410-419.

DOI: https://doi.org/10.1016/j.scitotenv.2015.08.153

Pandey A, Soccol C.R., Nigam P. \& Soccol V.T. (2000). Biotechnological potential of agro-industrial residues. I: sugarcane bagasse. Bioresource Technology 74: 69-80. DOI: https://doi.org/10.1016/S0960-8524(99)00142-X

Park E.Y., Naruse K. \& Kato T. (2012). One-pot bioethanol production from cellulose by co-culture of Acremonium cellulolyticus and Saccharomyces cerevisiae. Biotechnology for Biofuels 5: 64.

DOI: https://doi.org/10.1186/1754-6834-5-64

Peláez F., Martínez M.J. \& Martinez A.T. (1995). Screening of 68 species of basidiomycetes for enzymes involved in lignin degradation. Mycological Research 99(1): 37-42. DOI: https://doi.org/10.1016/S0953-7562(09)80313-4

Prado R.D.M., Caione G. \& Campos C.N.S. (2013). Filter cake and vinasse as fertilizers contributing to conservation agriculture. Applied and Environmental Soil Science 2013: Article ID 581984.

DOI: https://doi.org/10.1155/2013/581984

Rabelo S.C., da Costa A.C. \& Vaz Rossel C.E. (2015). Industrial waste recovery. In: Sugarcane, pp. 365-381. Academic Press, Cambridge, USA. DOI: 10.1016/b978-0-12-802239-9.00017-7

Ramos L.P., Silva L., Ballem A.C., Pitarelo A.P., Chiarello L.M. \& Silveira M.H.L. (2015). Enzymatic hydrolysis of steamexploded sugarcane bagasse using high total solids and low enzyme loadings. Bioresource Technology 175: 195. 
DOI: https://doi.org/10.1016/j.biortech.2014.10.087

Reshmi R. \& Sugunan S. (2013). Improved biochemical characteristics of cross-linked $\beta$-glucosidase on nanoporous silica foams. Journal of Molecular Catalysis B: Enzymatic 85(86): 111-118.

DOI: https://doi.org/10.1016/j.molcatb.2012.08.007

Saini J.K., Saini R. \& Tewari L. (2015). Lignocellulosic agriculture wastes as biomass feedstocks for secondgeneration bioethanol production: concepts and recent developments. 3 Biotech 5: 337-353. DOI: https://doi.org/10.1007/s13205-014-0246-5.

Sasaki C., Okumura R., Asakawa A., Asada C. \& Nakamura Y. (2012). Effects of washing with water on enzymatic saccharification and D-lactic acid production from steamexploded sugarcane bagasse. Journal of Material Cycles and Waste Management 14: 234-240.

DOI: https://doi.org/10.1007/s10163-012-0064-y

Schuster E., Dunn-Coleman N. \& Frisvad J. (2002). On the safety of Aspergillus niger-a review. Applied Microbiology and Biotechnology 59: 426-435.

DOI: https://doi.org/10.1007/s00253-002-1032-6

Sindhu R., Binod P. \& Pandey A. (2016). Biological pretreatment of lignocellulosic biomass-an overview. Bioresource Technology 199: 76-82.

DOI: https://doi.org/10.1016/j.biortech.2015.08.030

Singh P., Suman A., Tiwari P., Arya N., Gaur A. \& Shrivastava A.K. (2008). Biological pretreatment of sugarcane trash for its conversion to fermentable sugars. World Journal of Microbiology and Biotechnology 24: 667-673.

DOI: https://doi.org/10.1007/s11274-007-9522-4

Slininger P.J., Bothast R.J., Van Cauwenberge J.E. \& Kurtzman C.P. (1982). Conversion of D-Xylose to ethanol by the yeast Pachysolen tannophilus. Biotechnology and Bioengineering 24: 371.

DOI: https://doi.org/10.1002/bit.260240210

Soares A.C., Calado T. \& Armando V. ( 2013). Mycotoxin production by Aspergillus niger aggregate strains isolated from harvested maize in three Portuguese regions. Revista Iberoamericana de Micologías 30(1-3): 9-13.

DOI: https://doi.org/10.1016/j.riam.2012.05.002

Somerville C., Youngs H., Taylor C., Davis S.C. \& Long S.P. (2010). Feedstocks for lignocellulosic biofuels. Science 329: 790-792.

DOI: https://doi.org/10.1126/science.1189268

Sridevi A., Narasimha G. \& Rajasekhar Reddy B. (2009).
Production of cellulase by Aspergillus niger on natural and pretreated lignocellulosic wastes. International Journal of Microbiology 7: 580-592.

DOI: https://doi.org/10.5580/1884

Sridevi A., Narasimha G., Ramanjaneyulu G., Dileepkumar K., Rajasekhar Reddy B. \& Suvarnalatha Devi P. (2015). Saccharification of pretreated sawdust by Aspergillus niger cellulase. 3 Biotech 5: 883-892.

DOI: https://doi.org/10.1007/s13205-015-0284-7

Sumner J.B. (1921) Dinitrosalicylic acid: a reagent for the estimation of sugar in normal and diabetic urine. The Journal of Biological Chemistry 47: 5-9.

DOI: https://doi.org/10.1016/S0021-9258(18)86093-8

Taghizadeh-Alisaraei A., Abbaszadeh-Mayvan A. \& Hosseini S. H. (2019). Bio-ethanol production from a mixture of rice hull and orange peel wastes. Biofuels: 1-5.

DOI: https://doi.org/10.1080/17597269.2019.1655214

van den Brink J., Maitan-Alfenas G.P., Zou G., Wang C., Zhou Z., Guimarães V.M. \& de Vries R. (2014). Synergistic effect of Aspergillus niger and Trichoderma reesei enzyme sets on the saccharification of wheat straw and sugarcane bagasse. Biotechnology Journal 9(10): 1329-1338. DOI: https://doi.org/10.1002/biot.201400317

Velazquez-Cedeno M.A., Farnet A.M., Ferre E. \& Savoie J.M. (2004). Variations of lignocellulosic activities in dual cultures of Pleurotus ostreatus and Trichoderma longibrachiatum on unsterilized wheat straw. Mycologia 96(4): 712-719.

DOI: https://doi.org/10.1080/15572536.2005.11832919

Walter A., Dolzan P., Quilodrán O., de Oliveira J.G., da Silva C. \& Piacente F. (2011). Sustainability assessment of bioethanol production in Brazil considering land use change, GHG emissions and socio-economic aspects. Energy Policy 39: 5703 - 5716

DOI: https://doi.org/10.1016/j.enpol.2010.07.043

Yang X., Wang K., Wang H., Zhang J. \& Mao Z. (2016). Ethanol fermentation characteristics of recycled water by Saccharomyces cerevisiae in an integrated ethanolmethane fermentation process. Bioresource Technology 220: 609-614.

DOI: https://doi.org/10.1016/j.biortech.2016.08.040.

Zheng Y., Pan Z. \& Zhang R.N. (2009). Overview of biomass pretreatment for cellulosic production. International Journal of Agricultural and Biological Engineering 2: 51-68. 